

Research Article

\title{
Comparison of non-linear dynamic frame response under rec- orded and numerically generated accelerograms
}

\author{
Oscar Möller* ${ }^{1}$, Juan P. Ascheri ${ }^{1}$, Leandro E. Nardi 1 \\ 1 Instituto de Mecánica Aplicada y Estructuras (IMAE), Facultad Cs.Ex., Ingeniería y Agrimensura, \\ Universidad Nacional de Rosario, Rosario (Argentina), moller@fceia.unr.edu.ar \\ *Correspondence: moller@fceia.unr.edu.ar
}

Received: 15.03.2021; Accepted: 13.12.2021; Published: 31.12.2021

Citation: Möller, O., Ascheri, J. and Nardi, L. (2021). Comparison of non-linear dynamic frame response under recorded and numerically generated accelerograms. Revista de la Construcción. Journal of Construction, 20(3), 576-590. https://doi.org/10.7764/RDLC.20.3.576.

\begin{abstract}
The time history analysis of the linear and non-linear response of earthquake resistant structures is a tool increasingly used in practice and required by codes. In this paper, a set of 12 accelerograms was generated numerically with the spectral representation methodology. Another set of 15 accelerograms were selected from a database of earthquake records and scaled with a uniform factor so that the mean spectrum fits the design one. The non-linear dynamic response of two frames of different stiffness and resistance was obtained under the action of the two sets of accelerograms. The global force - displacement results showed a higher coefficient of variation for the set of recorded accelerograms, especially for the structure of lower resistance that has a strong non-linear incursion. The same tendency was obtained for the moment - curvature relationships of beam and column sections, with higher dispersions compared to the global results. In addition, the influence of the vertical acceleration component was analyzed, resulting in a higher incidence in the interior columns of the frames.
\end{abstract}

Keywords: seismic action, scaled accelerograms, nonlinear dynamics, concrete frames.

\section{Introduction}

The time history analysis of the linear and non-linear response of structures has become a widely used tool in current seismic evaluation and design techniques. Codes and recommendations accompany this trend, increasingly incorporating the use of non-linear static and dynamic analyses (ASCE 7-16, 2016; FEMA P-750, 2009; INPRES - CIRSOC 103, 2018). The selection and scaling of the accelerograms is very important in this process and significantly influences the results, since it can represent the greatest source of uncertainty and variability in the response estimates. This process includes the preliminary selection of representative records based on scenarios, refining the selected records to the minimum number required for analysis, and scaling of records to match the expected level of seismic hazard.

Various methods for selecting accelerograms that fit the target spectrum were published (Grant \& Diaferia, 2013; Hancock et al., 2006; Katsanos et al., 2010). (Ha \& Han, 2016) published a simple and efficient methodology to select soil movements with spectra approximate to the target spectrum in its mean value, variance and correlation. Alternatives for scaling the selected accelerograms were also presented by (Dehghani \& Tremblay, 2016). 
On the other hand, non-linear behaviour models of reinforced concrete elements for seismic actions have been developed (Filip C. Filippou \& Ahmad Issa, 1988; Taucer et al., 1991; Taylor et al., 2003), which have been implemented in computer programs that allow their use in practical engineering. The current analysis, design, optimization and performance evaluation procedures require a probabilistic treatment given the uncertainties existing in both the seismic action and in the variables that represent the capacity (FEMA P-58-I, 2012; Möller et al., 2017). Consequently, it is necessary to have a set of accelerograms that represent this randomness of the action within the seismic conditions of the site.

This paper discusses the choice of registered accelerograms and the different ways to scale them so that they are compatible with the prescriptions of the code (INPRES - CIRSOC 103, 2018) (IC 103) for the zone with the highest seismicity in Argentina. The artificial or numerical generation of acceleration-time functions is also analysed using the spectral representation technique (Shinozuka \& Deodatis, 1991), as another alternative to characterize seismic action.

The statistic of various parameters of the non-linear response of an earthquake-resistant concrete frame corresponding to a four-story office building is studied, with two variants: (a) Frame optimized to minimize the life cycle cost (Möller et al., 2015); (b) Frame dimensioned with the prescriptions of IC-103. In both cases, a set of registered accelerograms is considered, and it is compared with the results obtained by a set of numerically generated accelerograms. The importance of the vertical component registered simultaneously with the horizontal is also analysed. Finally, some interesting conclusions are obtained for the application of these procedures.

\section{Selection and scaling criteria of recorded accelerograms}

\subsection{Target spectrum}

First of all, it is necessary to define the target spectrum, in order to scale the accelerograms. The current trend is to work with two levels of seismic action: (i) Design earthquake, with 10\% probability of exceedance in 50 years; (ii) Maximum considered earthquake, associated with a $2 \%$ probability of exceedance in 50 years, used to verify the probability of collapse, for the design of energy dissipation elements, etc. There are many alternatives to build the spectrum that have evolved as a result of the greater number of earthquakes recorded and the gained experience. The uniform hazard spectrum (UHS) has been proposed and used, where each ordinate of the pseudo-acceleration spectrum has the same probability of exceedance. Then the uniform risk spectrum (URS) was defined, in which the ordinates of the spectrum present the same probability of collapse in the structures. The latter is compatible with the definition of the maximum considered earthquake (MCE), which is the maximum level of ground movement considered to be resisted by the structures.

Due to a certain conservatism observed with the UHS, URS and MCE spectra, (Baker, 2011) proposed the conditional mean spectrum (CMD). This provides the expected response spectrum, defined as the mean spectrum, conditioned on the occurrence of a target spectral acceleration value in the period of interest. Then, the accelerograms selected to fit that spectrum will be more consistent with those that occur naturally at the site. The Argentine Code IC-103 Part I defines the design spectrum based on a $10 \%$ probability of exceedance in 50 years. The seismic zoning is characterized by the effective acceleration of the soil, and the parameters that determine the design spectrum $(\mathrm{Ca}, \mathrm{Cv})$ depend on the seismic zone and the spectral type, this last one determined by the soil characteristics of the site.

\subsection{Selection of accelerograms}

The number of accelerograms to select, or generate numerically, has been modified with the advancement of knowledge. A minimum of 3 records was required for nonlinear analysis, and the maximum results were to be used for structural checks. If 7 or more records were used, then the verifications could be made with the mean values of the response. The current trend is to use at least 11 records (ASCE 7-16, 2016). In general, the response spectrum is the property of soil movement most correlated with the structural response, and therefore must be taken into account when selecting the accelerograms. The movements of the ground that can occur in a site depend on the possible sources of earthquakes, magnitude, distance and type of 
soil, characteristics that are reflected in the spectrum. Taking this into account, the selection criterion requires that the shape of the spectrum of the accelerogram must be similar to the target spectrum in the range of periods of interest.

Accelerograms are recorded with a time step between 0.001 and 0.02 seconds. In the selection, it should be considered that the sampling rate is fine enough to adequately represent the response for low periods, and should be of the order of 0.01 Tinf. In addition, the scale factor must be between 0.25 and 4 during the adjustment to the target spectrum. The Argentine Code IC-103 Part I prescribes for linear time history analysis, that each selected accelerogram from earthquake records, or generated numerically, must have maximum acceleration greater than the effective acceleration of the design spectrum, using a minimum of three accelerograms. When earthquake records are not available, accelerograms obtained by numerical simulation that meet the same conditions as the real records may be used. The use of other methods will require the special approval of the Authority of Application.

\subsection{Vertical component}

The amplitude of the vertical component of the ground acceleration generated by an earthquake has historically been considered as $2 / 3$ of the amplitude of the horizontal component. However, (Bozorgnia \& Campbell, 2004) show that this relationship may not be valid in some situations because it depends on the period of vibration, the distance to the focus, local soil conditions and the magnitude of the earthquake. For low periods the vertical / horizontal ratio generally exceeds $2 / 3$ and is lower for longer periods. Following this work, in ASCE 7-16 a spectrum of vertical pseudo-accelerations is proposed using parameters of horizontal acceleration, with the plafond between 0.05 and 0.15 seconds.

IC-103 Part I prescribes as a vertical seismic action, acting simultaneously with the horizontal, a constant value independent of the period and a function of the horizontal effective acceleration. In this work, the influence of the vertical component on the normal forces of the columns is analysed, using non-linear dynamic analysis applying simultaneously the horizontal and vertical components of recorded earthquakes.

\subsection{Scaling of accelerograms}

There are different criteria for scaling accelerograms, some of them described below.

\subsubsection{ASCE 7-16}

ASCE 7-16 presents options for scaling accelerograms, recorded or numerically generated. The range of periods where the adjustment is made is first analysed and then the scaling factor.

a) Range of periods to consider for adjustment

For linear analysis, the range is defined from 0.8 Tinf to 1.2 Tsup, where Tinf and Tsup are the shortest and longest periods that participate significantly in the response. For nonlinear analysis, the adjustment range is from $0.2 \mathrm{~T} 1$ to $2.0 \mathrm{~T} 1$, where $\mathrm{T} 1$ is redefined as the maximum fundamental period of the building considering the two main directions and the torsional rotation. The lower limit is complemented by an additional requirement that must also capture the periods necessary for a $90 \%$ mass participation in both directions of the building.

b) Scaling factor

Non-uniform scaling: Applies to real or artificial ground motion, so that its pseudo-acceleration response spectrum fits the target spectrum well. It is interpreted as a good fit when the mean response spectrum calculated with the scaled records is not above or below the target spectrum by more than $10 \%$ over the range of the period of interest.

Uniform scaling: A single factor is applied to all ground motion. It preserves the variability that naturally exists between one record and another, as well as the frequency content of each record. However, individual record can significantly exceed 
the ordinate of the target spectrum in some periods, which may tend to exaggerate the importance of higher modes in some structures. The adjustment is made with the maximum spectrum of each horizontal direction, instead of the spectrum obtained with the square root of the sum of the squares of the individual spectrums. This change was made to be consistent with the maximum considered earthquake, which is now explicitly defined as movement in the maximum direction.

Scaling should ensure that the average spectrum is not less than $90 \%$ of the target spectrum for any period within the range of periods of interest.

\subsubsection{IC-103 Part I}

It refers only to the linear response in time where it must be verified that for the periods between $0.2 \mathrm{~T}$ and $1.5 \mathrm{~T}$, the mean of the ordinate of the response spectra for the accelerograms analyzed will not be less than the ordinate corresponding to the spectrum of design, where $\mathrm{T}$ is the fundamental period.

\subsubsection{Other proposals}

Other accelerogram scaling methods were proposed, see (Dehghani \& Tremblay, 2016).

- Adjustment in the fundamental period of the structure: The record is scaled so that the spectral ordinate matches with that of the target spectrum at the fundamental period T1 of the structure. The structure is assumed to remain essentially elastic and the fundamental mode predominates in the response. However, this assumption may not represent the real behaviour of the structure, since modes of higher frequency might participate, resulting in shorter periods, and a non-linear behaviour might probably occur, which implicates the formation of an energy dissipation mechanism that lengthens the dominant period. Thus, the adjustment in a single period can mean values of spectral ordinates very different from the targets for other values of periods that participate in the response.

- Average adjustment in a range of periods: To improve the adjustment only in the fundamental period, it was proposed to calculate an adjustment factor as an average adjustment in a set of periods from $0.2 \mathrm{~T} 1$ to $1.5 \mathrm{~T} 1$ according to ASCE 7-10, thus considering the influence of higher modes and the elongation of the fundamental period due to nonlinear behaviour. In ASCE 7-16 the range was extended to 2.0 T1.

- Adjustment by matching spectral intensity: The record is scaled by matching the area under the record spectrum between $0.2 \mathrm{~T} 1$ to $1.5 \mathrm{~T} 1(2.0 \mathrm{~T} 1)$ with the area under the target spectrum in the same range of periods.

- Least squares adjustment: The record scaling factor is obtained by minimizing the square of the difference between the record spectrum and the target spectrum in the range of periods of interest.

\subsubsection{General considerations}

The adjustment can begin by initially applying scale factors to the individual records, with any of the criteria described. Then a single adjustment factor is collectively applied to all the records so that the average spectrum of the set satisfies the code requirement, target spectrum, within the range of periods of interest.

\section{Frame with non-linear behavior}

A four-story office building located in the city of Mendoza, Argentina, is analysed. Figure 1 shows the plant and the elevation of the frames in the $\mathrm{X}$ direction, which is the direction analysed for the seismic movement. 


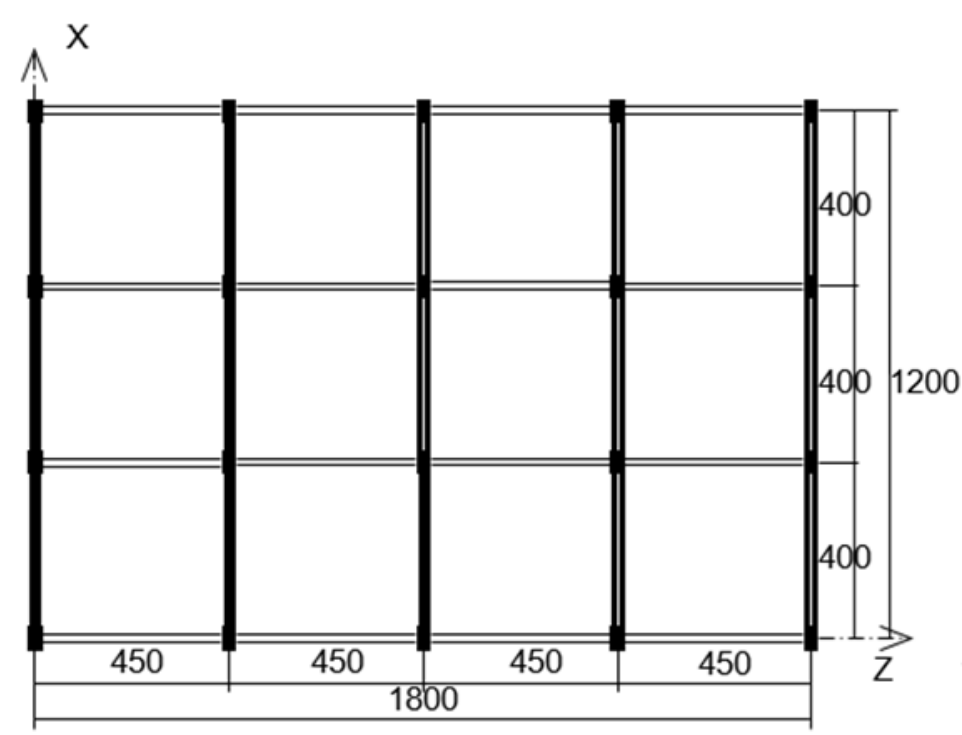

Plant

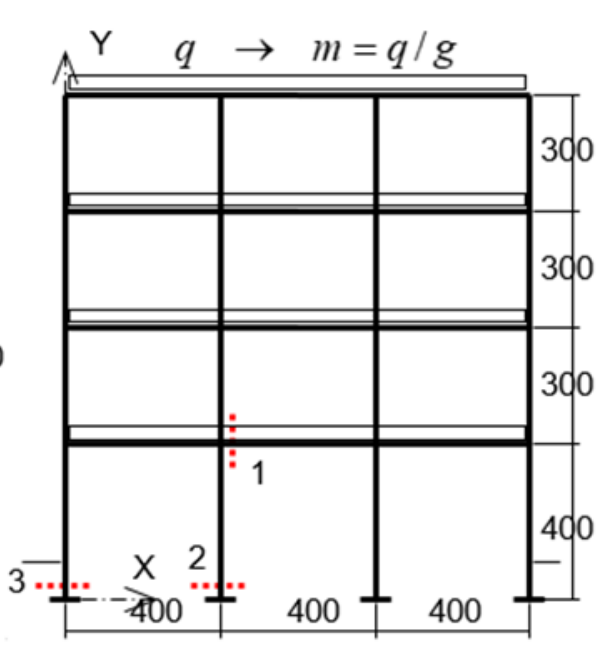

Frame

Figure 1. Building plant and a typical frame in X direction. Unit: $\mathrm{cm}$. Source: self-elaboration

The behaviour for two very different solutions is studied: (a) Optimized frame (Möller et al., 2017) with fundamental period of vibration $\mathrm{T}=0.50 \mathrm{~s}$; (b) Frame dimensioned with IC-103 that has a period T=0.92 s. Table 1 summarizes the characteristics of the sections.

Table 1. Design variables for the analysed structures. Source: self-elaboration

\begin{tabular}{ccccc}
\hline Structure & \multicolumn{2}{c}{$\mathrm{T}=0.50 \mathrm{~s}$} & \multicolumn{2}{c}{$\mathrm{T}=0.92 \mathrm{~s}$} \\
\hline Floor & $1-2$ & $3-4$ & $1-2$ & $3-4$ \\
\hline Beam sections [cm] & $20 / 64$ & $20 / 54$ & $20 / 50$ & $20 / 45$ \\
\hline Column sections [cm] & $30 / 85$ & $30 / 64$ & $30 / 60$ & $30 / 45$ \\
\hline Reinforcement ratio for beams (span) & 0.0119 & 0.0119 & 0.00452 & 0.00349 \\
\hline Reinforcement ratio for beams (support) & 0.0104 & 0.0104 & 0.00804 & 0.00621 \\
\hline Reinforcement ratio for columns & 0.0184 & 0.0184 & 0.01117 & 0.01098 \\
\hline
\end{tabular}

The properties of the materials are $f^{\prime} c=25 M P a$ for concrete and $f y=420 M P a$ for steel. The mass per unit length in beams is $m=3.00 \cdot 10^{-4} \mathrm{KNs}^{2} / \mathrm{cm}^{2}$. The confining pressure given by the transverse reinforcement is $\mathrm{fr}=0.10 \mathrm{f}^{\prime} \mathrm{co}$. With these data, the moment curvature relationships were obtained, for 4 complete cycles up to the failure curvature, using a section model with discretization in fibres, and then the rectified envelope with bilinear relationship.

\section{Non-linear static analysis (push-over)}

With a model of non-linear reinforced concrete bar element (Möller \& Foschi, 2003) the non-linear static analysis (pushover) of each frame was performed, and the results are shown in Figure 2. 


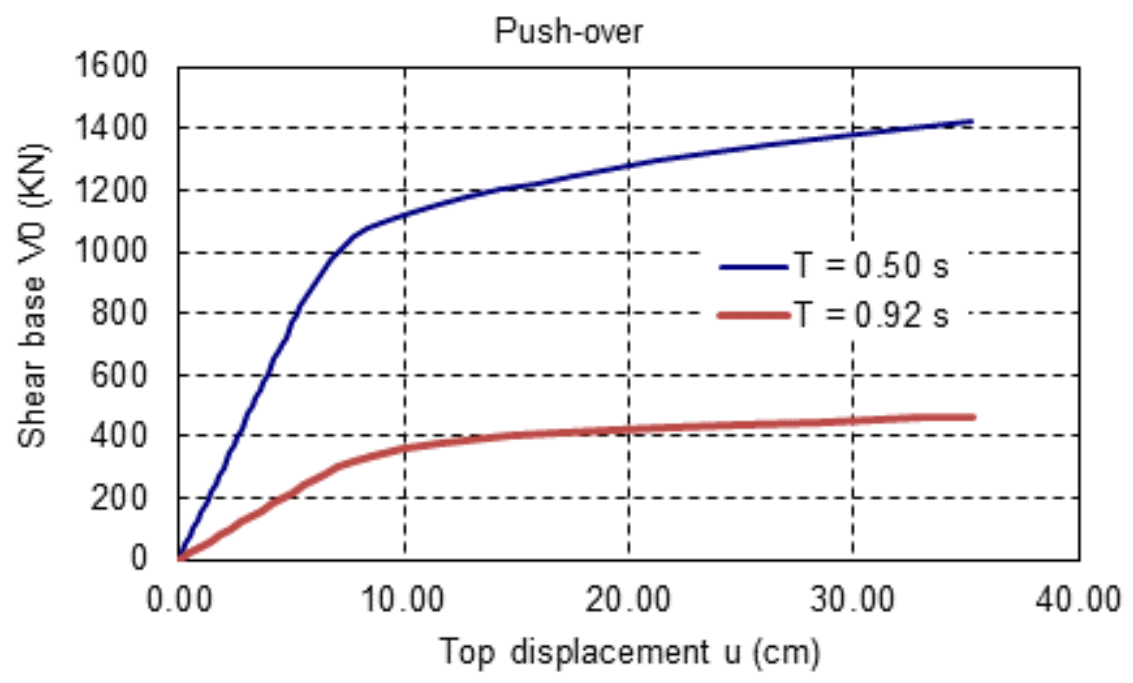

Figure 2. Nonlinear static analysis (push-over).

The stiffness and resistance of the optimized frame $(\mathrm{T}=0.50 \mathrm{~s})$ is significantly higher than that of the frame dimensioned with the code $(\mathrm{T}=0.92 \mathrm{~s})$. The minimum life cycle cost is obtained with higher resistance, which means higher initial cost, but with lower cost of repair for damages and social costs when an earthquake occurs (Möller et al., 2017). In both cases the maximum displacement is associated with the failure of a section when its damage index (Park and Ang) reaches the value of 1.00. For this maximum displacement, very similar between both frames, the maximum floor distortions are $3.2 \%$ and $3.1 \%$ respectively. Other results of interest are the yield displacement $\mathrm{u}_{\mathrm{y}}=7.1 \mathrm{~cm}$ and $\mathrm{u}_{\mathrm{y}}=8.8 \mathrm{~cm}$, and the displacement ductility $\mu=5.0$ and $\mu=4.0$ respectively.

\section{Numerically generated accelerograms}

The ground movement is represented as a stochastic process like filtered white noise with a power spectral density function given by:

$$
S_{X X}(f)=S_{0} \frac{1+4 \xi_{g}^{2}\left(f / f_{g}\right)^{2}}{\left[1-\left(f / f_{g}\right)^{2}\right]^{2}+4 \xi_{g}^{2}\left(f / f_{g}\right)^{2}} \frac{\left(f / f_{f}\right)^{4}}{\left[1-\left(f / f_{f}\right)^{2}\right]^{2}+4 \xi_{f}^{2}\left(f / f_{f}\right)^{2}}
$$

where $S_{0}$ is the power spectral density of the white noise, $f_{g}$ and $\xi_{g}$ are the characteristic ground frequency and its damping ratio, and $\mathrm{f}_{\mathrm{f}}$ and $\xi_{\mathrm{f}}$ are the parameters of the high pass filter that attenuates the very low frequency components. Applying the spectral representation method (Shinozuka \& Deodatis, 1991) and using eq.(1), a member of the process, that is, an artificial accelerogram, is obtained with:

$$
x(t)=I(t) \cdot \sum_{n=1}^{N F R}\left\{4 S_{X X}(n \Delta f) \cdot\left[1+\delta_{S} R_{N}\right] \Delta f\right\}^{1 / 2} \sin \left(2 \pi n \Delta f t+\theta_{n}\right)
$$

where NFR is the number of frequencies between 0 and $\mathrm{f}_{\max }$, and must be $N F R \geq f_{\max } T_{0}$ where $\mathrm{T}_{0}$ is the duration of the record to be generated; $\delta_{S}$ is a coefficient of variation that takes into account the uncertainty in the ordinate of $S_{X x}$ and $R_{N}$ is a standard normal variable; $\theta_{\mathrm{n}}$ are the random phase angles with uniform distribution between 0 and $2 \pi$; $\mathrm{I}(\mathrm{t})$ is a modulation function that considers non-stationarity in amplitudes. The accelerogram thus generated is corrected for the baseline to minimize the root mean square value of the velocity, and it is scaled to adjust the maximum acceleration $\mathrm{a}_{\mathrm{G}}$. 


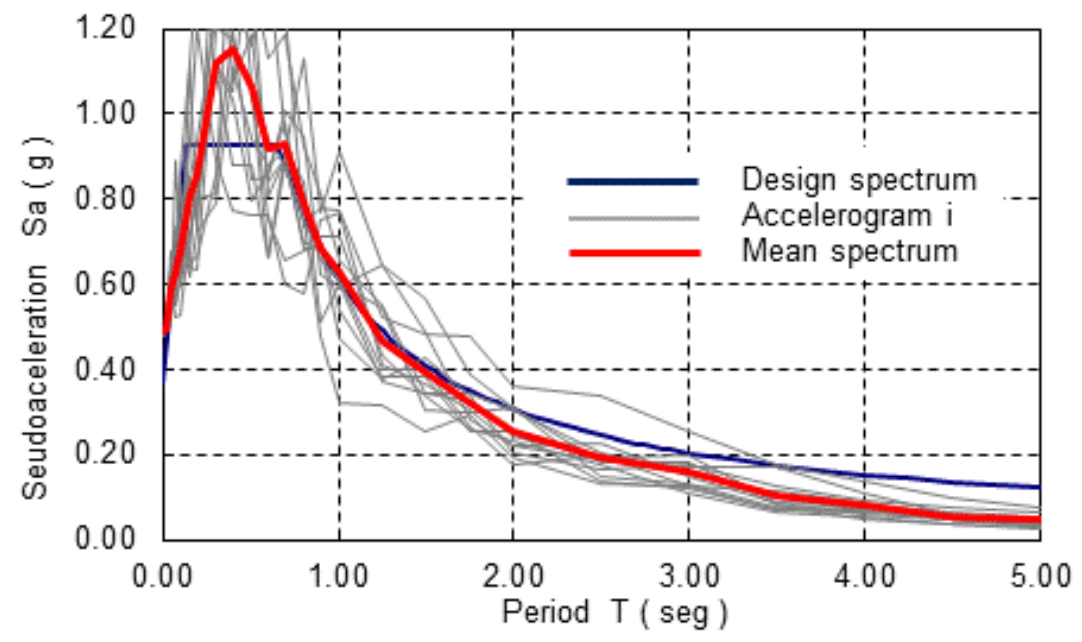

Figure 3. Spectra of numerically generated accelerograms.

With this technique 12 accelerograms are generated with $\mathrm{aG}=0.35 \mathrm{~g}$, which is the ground acceleration for the design spectrum. Then, following ASCE 7-16, they are all scaled with a single factor F $=1.39$ so that the mean spectrum is not less than $90 \%$ of the target spectrum for any period within the range of periods of interest, $0.2 \mathrm{~T} 1$ a $2.0 \mathrm{~T} 1$, which results from $0.10 \mathrm{~s}$ to $1.84 \mathrm{~s}$ to cover the two studied frames. Figure 3 shows the spectra of each numerically generated accelerogram scaled with a single factor, the average spectrum, and the IC 103 design spectrum for the region of highest seismicity in Argentina.

\section{Recorded accelerograms}

From the PEER base (Pacific Earthquake Engineering Research Center, 2019), 12 records of earthquakes occurred in the world were selected with the criterion that the shape of the response spectrum is similar to the design spectrum. Another 3 earthquakes were added, one from Argentina, another from Loma Prieta and the other from Chile. Table 2 shows the whole set of acceleration registers. This condition implicitly takes into account the correspondence with spectral type 1 of IC-103 Part I. From each record, the horizontal component with the greatest maximum acceleration is chosen and a factor is applied to it so that the maximum acceleration is $\mathrm{a}_{\mathrm{G}}=0.35 \mathrm{~g}$. The same factor applies to the vertical component. This set of accelerograms is then uniformly scaled with a factor $\mathrm{F}=1.65$ so that the mean spectrum is not less than $90 \%$ of the target spectrum for any period within the range of periods of interest.

Table 2. Recorded earthquake data. Source: PEER base

\begin{tabular}{lccc}
\hline \multicolumn{1}{c}{ Earthquake } & Comp 1 (horiz) & $\begin{array}{c}\mathrm{A}_{\max }(\mathrm{g}) \\
\text { Comp 2 (horiz) }\end{array}$ & Comp 3 (vert) \\
\hline 1. El Centro - 1940 & -0.2808 & -0.2107 & -0.1781 \\
\hline 2. San Fernando - 1971 & 0.3205 & 0.2752 & -0.1666 \\
\hline 3. Managua - 1972 & 0.3718 & 0.3295 & 0.3065 \\
\hline 4. Tabas, Iran -1978 & 0.3239 & 0.4094 & 0.1904 \\
\hline 5. Imperial Valley-06 - 1979 & -0.5987 & 0.7769 & -0.5316 \\
\hline 6. Northridge - 1994 & -0.8832 & -0.3699 & -0.2305 \\
\hline 7. Kobe - 1995 & 0.2403 & 0.3242 & 0.1714 \\
\hline 8. Chi-Chi, Taiwan (a) -1999 & -1.0089 & -0.4311 & 0.3204 \\
\hline 9. Chi-Chi, Taiwan (b) - 1999 & -0.3533 & -0.2294 & -0.1936 \\
\hline 10. Hector Mine - 1999 & 0.2655 & 0.3282 & -0.1487 \\
\hline 11. Niigata, Japan - 2004 & 0.3501 & 0.4175 & -0.3245 \\
\hline 12. Chuetsu-oki, Japan - 2007 & 0.3186 & 0.2840 & 0.1713 \\
\hline 13. Caucete, Argentina - 1977 & 0.1906 & 0.1932 & 0.1534 \\
\hline 14. Loma Prieta - 1989 & 0.4785 & 0.6297 & 0.4394 \\
\hline
\end{tabular}




\begin{tabular}{llll}
\hline 15. Viña del Mar, Chile - 1985 & 0.3200 & 0.2116 & -0.1435 \\
\hline
\end{tabular}

Figure 4 shows the spectra of each scaled accelerogram, the average spectrum, and the design spectrum of IC-103 for the region of highest seismicity in Argentina.

The shape of the response spectra of the selected accelerograms roughly follows the shape of the design spectrum, but they present a greater dispersion with respect to the numerically generated accelerograms, due to the different conditions of the sites where they were recorded.

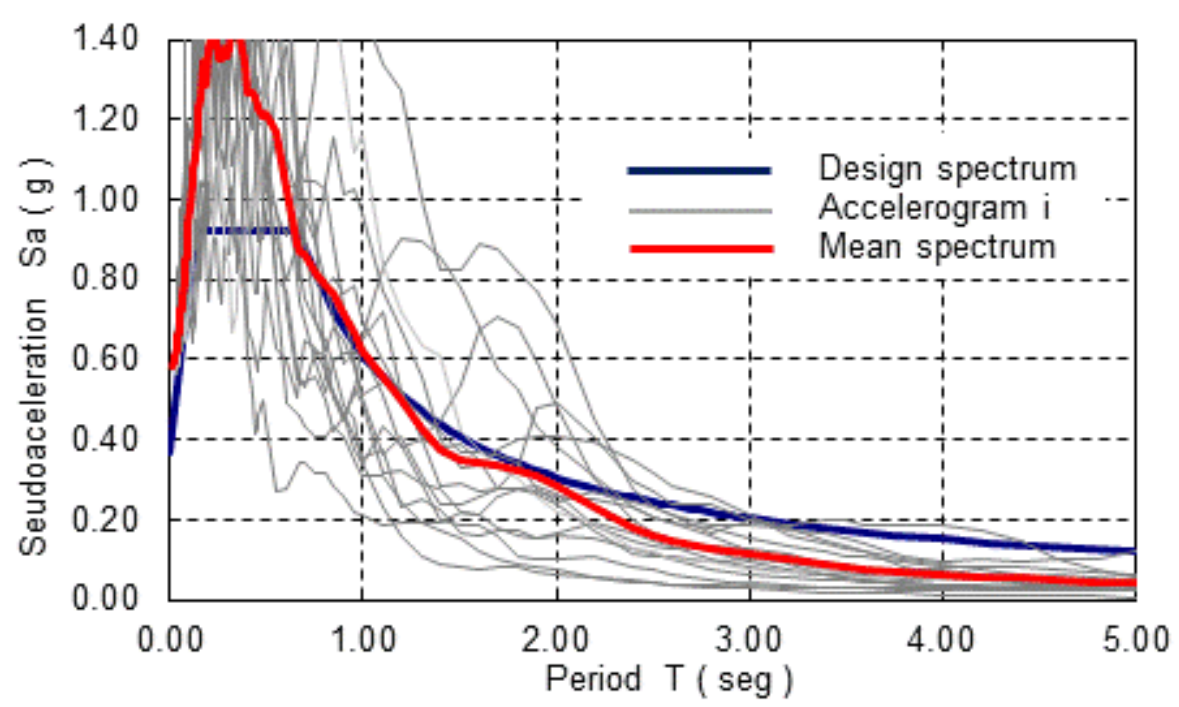

Figure 4. Recorded accelerogram spectra. Source: self-elaboration

The vertical components, simultaneous with the horizontal ones, were also scaled with the same factor 1.65 to maintain the same proportions.

\section{Non-linear dynamic analysis}

The set of 12 numerically generated accelerograms and the set of 15 registered accelerograms, after scaling them as described in sections 5 and 6 , are applied to each structure analysed. The dynamic analysis is performed with a non-linear reinforced concrete bar element model, by direct integration of the equations with Newmark's method and equilibrium iterations at each time step with Newton Raphson's iterative algorithm.

\subsection{General results of the structures}

For each structure and each set of accelerograms, the results of maximum horizontal displacement on the top floor $\mathrm{U}_{\max }$ with the associated shear base $\mathrm{V}_{0}$, and the maximum shear base $\mathrm{V}_{0 \max }$ with the associated displacement $\mathrm{U}$, are presented in Figure 5, overlaid with the push-over of each structure. As an example, Figure 6 presents the history of the $\mathrm{V}_{0}-\mathrm{U}$ response of the structure with $\mathrm{T}=0.92 \mathrm{~s}$ for the action of the Chi-Chi, Taiwan earthquake (a) (No. 8 in Table 2). Table 3 presents the statistics of all the results.

In the structure of $\mathrm{T}=0.50 \mathrm{~s}$, the dynamic action with the registered accelerograms originate maximum displacement and mean value slightly greater than with the action of numerically generated accelerograms. A greater dispersion is also observed with a coefficient of variation 0.226 compared to 0.176 . The structure reaches the energy dissipation mechanism but with little incursion in the post-yield period. No significant differences are observed between $V_{0 \max }-U$ and $V_{0}-U_{\max }$ for both the generated and recorded accelerograms. 
These results derive from the optimization process where the minimum life cycle cost is achieved with a higher initial cost but lower repair costs and social costs, when compared to the design according to IC 103.
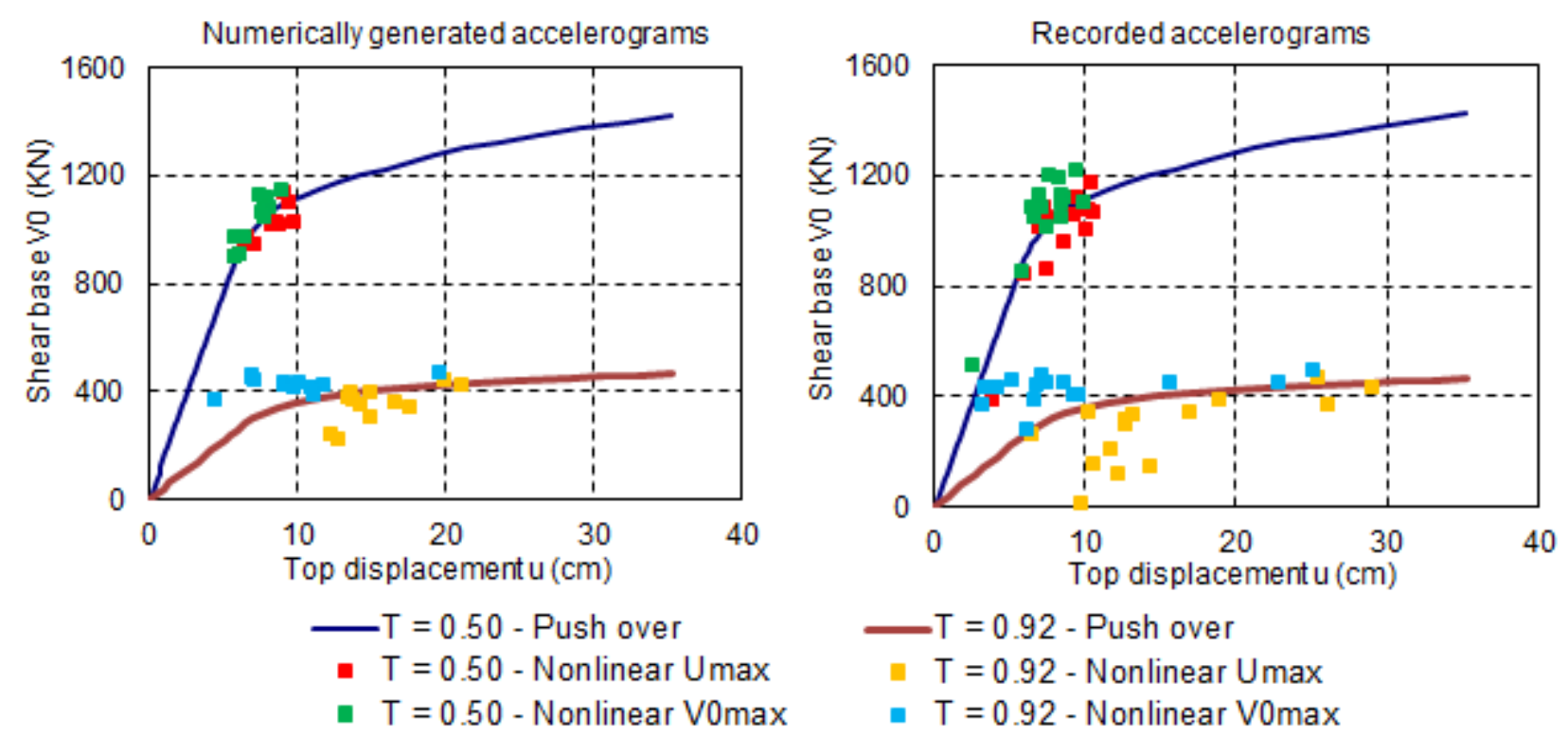

Figure 5. Results of maximum shear base V0 and top displacement U. Source: self-elaboration

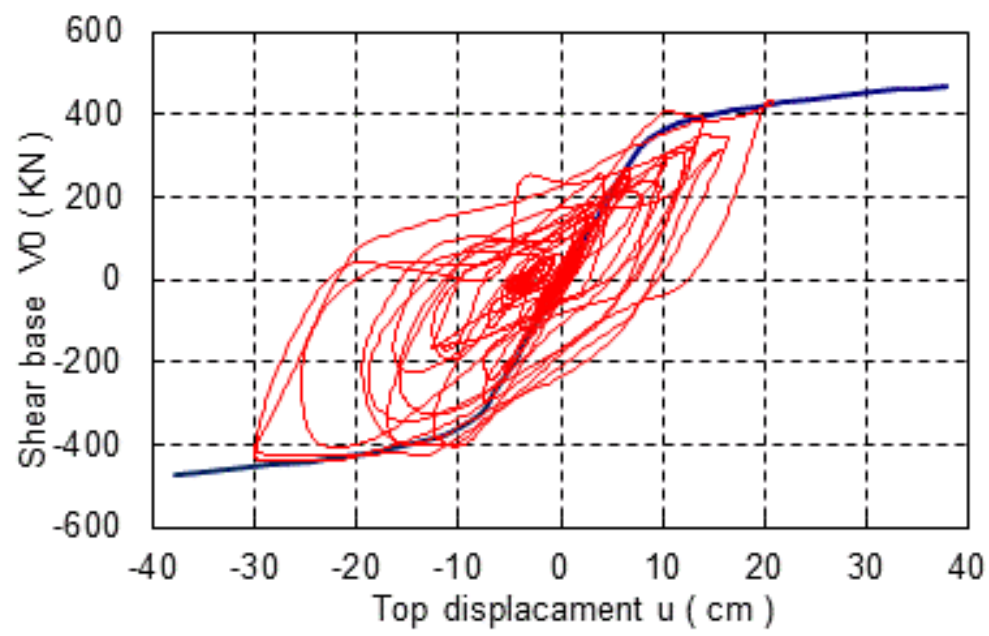

Figure 6. Response to the Chi-Chi, Taiwan earthquake (1999).

In the structure of $\mathrm{T}=0.92 \mathrm{~s}$, dimensioned with the prescriptions of IC 103, there is a significant difference between the results for generated accelerograms and those registered. The maximum displacements $U_{\max }$ have a ratio of 29.09/21.13=1.38, but the mean values are almost equal to $15.50 \mathrm{~cm} \approx 15.37 \mathrm{~cm}$. The greatest dispersion in the results with recorded accelerograms is quantified with the coefficient of variation of $U_{\max }$, with a value of 0.434 compared to 0.182 obtained with the numerically generated accelerograms. Greater differences are also observed between $\mathrm{V}_{0 \max }-\mathrm{U}$ and $\mathrm{V}_{0}-\mathrm{U}_{\max }$ for both the generated and recorded accelerograms, with respect to the structure of $\mathrm{T}=0.50 \mathrm{~s}$. 
Table 3. Results statistics $\mathrm{V}_{0}-\mathrm{U}$. Source: self-elaboration

\begin{tabular}{ccccccccc}
\hline & \multicolumn{3}{c}{ Generated accerograms } & \multicolumn{3}{c}{ Recorded accelerograms } \\
\hline & $\begin{array}{c}\mathrm{V}_{0} \\
(\mathrm{KN})\end{array}$ & $\begin{array}{c}\mathrm{U}_{\max } \\
(\mathrm{cm})\end{array}$ & $\begin{array}{c}\mathrm{V}_{0 \max } \\
(\mathrm{KN})\end{array}$ & $\begin{array}{c}\mathrm{U} \\
(\mathrm{cm})\end{array}$ & $\begin{array}{c}\mathrm{V}_{0} \\
(\mathrm{KN})\end{array}$ & $\begin{array}{c}\mathrm{U}_{\max } \\
(\mathrm{cm})\end{array}$ & $\begin{array}{c}\mathrm{V}_{0 \text { max }} \\
(\mathrm{KN})\end{array}$ & $\begin{array}{c}\mathrm{U} \\
(\mathrm{cm})\end{array}$ \\
\hline & & & & \multicolumn{2}{c}{ Structure $\mathrm{T}=0.50 \mathrm{~s}$} & & \\
\hline Maximum & 1027.7 & 9.809 & 1140.2 & 8.992 & 1069.3 & 10.59 & 1214.8 & 9.503 \\
\hline Minimum & 893.45 & 5.785 & 893.45 & 5.785 & 389.27 & 3.878 & 512.13 & 2.671 \\
\hline Mean value & 1005.2 & 7.864 & 1030.0 & 7.213 & 992.70 & 8.461 & 1054.4 & 7.535 \\
\hline Standard deviation & 73.97 & 1.382 & 84.88 & 1.055 & 190.66 & 1.910 & 174.05 & 1.744 \\
\hline COV & 0.074 & 0.176 & 0.082 & 0.146 & 0.192 & 0.226 & 0.165 & 0.231 \\
\hline Maximum & & & & Structure $\mathrm{T}=0.92 \mathrm{~s}$ & & & \\
\hline Minimum & 419.02 & 21.13 & 463.80 & 19.64 & 428.70 & 29.09 & 494.19 & 25.17 \\
\hline Mean value & 242.70 & 12.27 & 364.95 & 4.445 & 263.06 & 6.528 & 281.10 & 6.145 \\
\hline Standard deviation & 67.79 & 15.50 & 424.46 & 9.801 & 276.99 & 15.37 & 424.74 & 9.468 \\
\hline COV & 0.192 & 0.182 & 0.071 & 0.386 & 0.459 & 0.434 & 0.121 & 0.703 \\
\hline
\end{tabular}

These results are consistent with Figures 3 and 4, where the average spectra are equal and then the average value of the maximum displacements is also equal. The greater dispersion in the response spectra of the recorded accelerograms produces greater dispersion in the $\mathrm{U}_{\max }$ displacements when the structure significantly enters nonlinear behaviour. The greater variation in the frequency content of the recorded accelerograms justifies the differences between $\mathrm{V}_{0 \max }-\mathrm{U}_{\text {and }} \mathrm{V}_{0}-\mathrm{U}_{\max }$ by the participation of different modes of vibration, which in turn are modified according to the degree of non-linear incursion.

The results of the nonlinear dynamic analysis show that the maximum shear base $\mathrm{V}_{0 \max }$ is not directly associated with the maximum displacement $U_{\max }$ as obtained from a static push-over analysis. However, the push-over curve is a good indicator of the average response.

\subsection{Results in beam and column sections}

\subsubsection{Moment-curvature relationships}

For the beam section in the interior support (see section " 1 " of Figure 1 ) of the two analysed structures, with periods $\mathrm{T}=0.50$ $\mathrm{s}$ and $\mathrm{T}=0.92 \mathrm{~s}$, the monotonic curves of the moment-curvature relationships are shown in Figure 7 together with maximum curvature results from nonlinear dynamic analyzes for sets of numerically generated accelerograms and recorded accelerograms.

The greater general resistance of the optimized structure, $\mathrm{T}=0.50 \mathrm{~s}$, observed in Figure 2 and Figure 5, is also manifested in the greater bending moment capacity of the beam section, with respect to the structure of period $\mathrm{T}=0.92 \mathrm{~s}$. The results of the non-linear dynamic analysis show greater non-linear incursion for the section with lower resistance, which means greater demand for curvature ductility. In addition, there is greater dispersion in the maximum curvatures for the set of registered accelerograms with respect to those generated numerically, with the same justification as that explained for the overall results of the structure. 

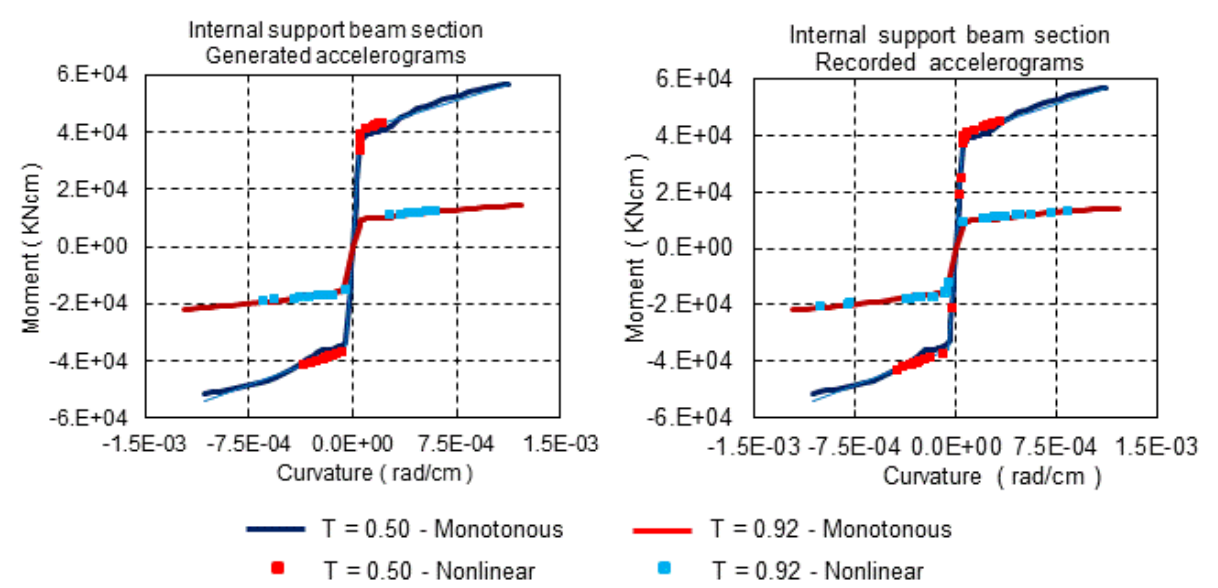

Figure 7. Results of moment - curvature for beam section.

In Figure 8 the results for the lower section of the interior column are presented (see section "2" of Figure 1), with observations similar to the beam section.
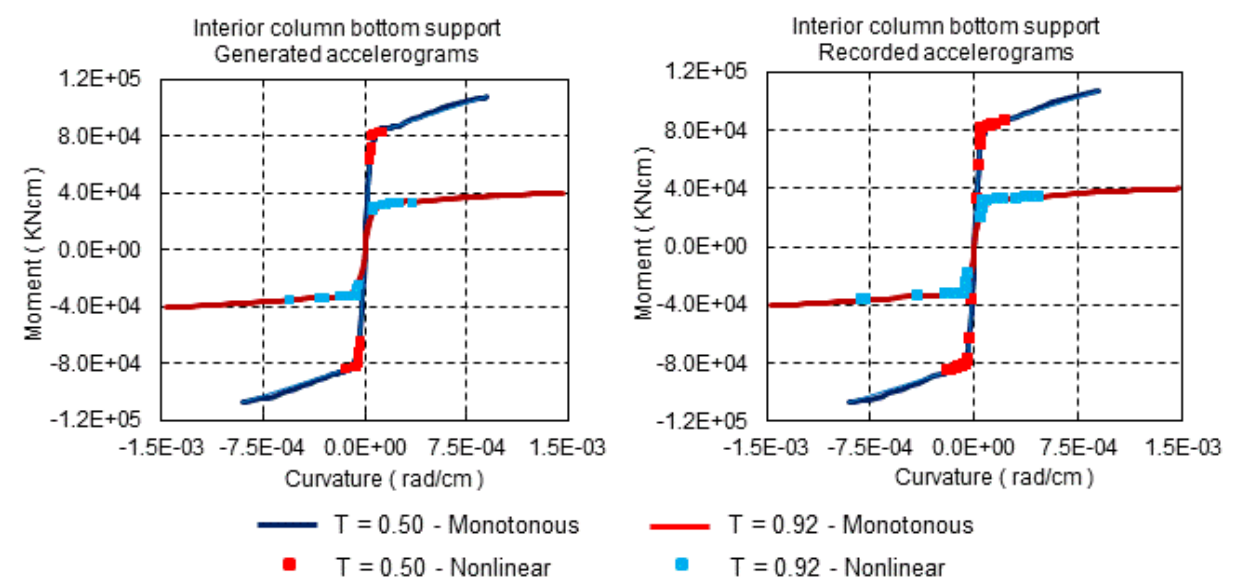

Figure 8. Results of moment - curvature for interior column.

To statistically characterize the results, the maximum and minimum mean values and the coefficients of variation of the studied beam and column sections are presented in Table 4, for the sets of numerically generated accelerograms and recorded accelerograms.

Table 4. Statistics of curvatures in beam and column sections.

\begin{tabular}{|c|c|c|c|c|c|c|}
\hline \multirow{2}{*}{$\begin{array}{c}\text { Positive and nega- } \\
\text { tive curvatures } \\
\text { [rad/cm] }\end{array}$} & \multicolumn{3}{|c|}{ Generated accelerograms } & \multicolumn{3}{|c|}{ Recorded accelerograms } \\
\hline & Beam & Interior column & Exterior column & Beam & Interior column & Exterior column \\
\hline & \multicolumn{6}{|c|}{ Structure $\mathrm{T}=0.50 \mathrm{~s}$} \\
\hline Mean value (+) & $1.183 \mathrm{E}-04$ & $6.304 \mathrm{E}-05$ & $5.645 \mathrm{E}-05$ & $1.422 \mathrm{E}-04$ & $8.288 \mathrm{E}-05$ & $7.259 \mathrm{E}-05$ \\
\hline $\mathrm{COV}(+)$ & 0.554 & 0.480 & 0.492 & 0.717 & 0.691 & 0.656 \\
\hline Mean value (-) & $-2.016 \mathrm{E}-04$ & $-5.603 \mathrm{E}-05$ & $-4.791 \mathrm{E}-05$ & $-2.705 \mathrm{E}-04$ & $-8.227 \mathrm{E}-05$ & $-6.787 \mathrm{E}-05$ \\
\hline \multirow[t]{2}{*}{ COV (-) } & 0.384 & 0.541 & 0.526 & 0.382 & 0.602 & 0.598 \\
\hline & \multicolumn{6}{|c|}{ Structure $\mathrm{T}=0.92 \mathrm{~s}$} \\
\hline Mean value $(+)$ & $4.681 \mathrm{E}-04$ & $1.691 \mathrm{E}-04$ & $1.325 \mathrm{E}-04$ & $3.944 \mathrm{E}-04$ & $1.746 \mathrm{E}-04$ & $1.539 \mathrm{E}-04$ \\
\hline $\mathrm{COV}(+)$ & 0.216 & 0.498 & 0.430 & 0.496 & 0.826 & 0.847 \\
\hline Mean value (-) & $-3.007 \mathrm{E}-04$ & $-1.694 \mathrm{E}-04$ & $-1.622 \mathrm{E}-04$ & $-3.442 \mathrm{E}-04$ & $-2.158 \mathrm{E}-04$ & $-1.935 \mathrm{E}-04$ \\
\hline $\operatorname{COV}(-)$ & 0.585 & 0.907 & 0.975 & 0.863 & 1.180 & 1.195 \\
\hline
\end{tabular}


The greater dispersion in the results for the recorded accelerograms than for those generated numerically observed in Figure 7 and Figure 8, is now quantified with the coefficients of variation. The average of the variation coefficients for the numerically generated accelerograms is $\mathrm{COVm}=0.549$, while for the recorded accelerograms is $\mathrm{COVm}=0.754$. The ratio is 0.754 / $0.549=1.37$. Comparison of these "local" results of curvatures with the "global" results of horizontal displacements on the top floor, shows that: (i) The mean values of curvature are higher for recorded accelerograms, while the mean values of global displacements remain the same as those obtained with numerically generated accelerograms; (ii) The coefficients of variation of the local curvature results are greater than the coefficients of variation of the global displacements, for both types of accelerograms.

This last observation is indicating that the greater dispersions in the local results are then compensated for the global result.

\subsubsection{Influence of vertical acceleration}

Table 5 presents the results of axial forces in columns obtained with non-linear dynamic analysis applying simultaneously the horizontal and vertical components of recorded earthquakes, and they are compared with the results of applying only the horizontal component. Positive axial forces indicate compression, and negative tension. In general, the coefficient of variation is used as a measure of the dispersion of the results within the set of accelerograms. However, the minimum mean values are close to zero for the outer column of the structure of $\mathrm{T}=0.92 \mathrm{~s}$, so the standard deviation is also included because the coefficient of variation has very high values that alter its interpretation.

Table 5. Statistics of axial forces in column sections.

\begin{tabular}{|c|c|c|c|c|}
\hline \multirow[t]{2}{*}{$\begin{array}{l}\text { Axial forces } \\
{[\mathrm{KN}]}\end{array}$} & \multicolumn{2}{|c|}{$\begin{array}{l}\text { Recorded accelerograms: } \\
\text { horizontal component }\end{array}$} & \multicolumn{2}{|c|}{$\begin{array}{l}\text { Recorded accelerograms: } \\
\text { horizontal and vertical com- } \\
\text { ponent }\end{array}$} \\
\hline & $\begin{array}{c}\text { Interior col- } \\
\text { umn }\end{array}$ & $\begin{array}{c}\text { Exterior col- } \\
\text { umn }\end{array}$ & $\begin{array}{c}\text { Interior col- } \\
\text { umn }\end{array}$ & $\begin{array}{c}\text { Exterior col- } \\
\text { umn }\end{array}$ \\
\hline & \multicolumn{4}{|c|}{ Structure $\mathrm{T}=0.50 \mathrm{~s}$} \\
\hline Mean maximum value & 532.0 & 844.9 & 698.3 & 874.5 \\
\hline $\mathrm{COV}(\max )$ & 0.013 & 0.127 & 0.129 & 0.135 \\
\hline Mean minimum value & 463.9 & -336.3 & 297.5 & -361.0 \\
\hline $\mathrm{COV}(\min )$ & 0.019 & 0.245 & 0.254 & 0.279 \\
\hline & \multicolumn{4}{|c|}{ Structure $\mathrm{T}=0.92 \mathrm{~s}$} \\
\hline Mean maximum value & 524.0 & 466.2 & 636.7 & 466.9 \\
\hline COV (max) & 0.013 & 0.064 & 0.295 & 0.289 \\
\hline Mean minimum value & 478.9 & 27.6 & 299.3 & 5.7 \\
\hline Standard deviation $(\mathrm{min})$ & & 22.9 & & 30.3 \\
\hline $\operatorname{COV}(\min )$ & 0.017 & 0.829 & 0.321 & 5.34 \\
\hline
\end{tabular}

The inner column, section " 2 " of Figure 1, has a low effect on normal stress due to the horizontal component of the seismic action. For the structure of $\mathrm{T}=0.50 \mathrm{~s}$, the mean value of the maximums is $532.0 \mathrm{KN}$ compared to the minimum mean value of 463.9 KN, both compression, with a difference of $68.1 \mathrm{KN}$. A smaller difference of $45.1 \mathrm{KN}$ for the structure of T=0.92 $\mathrm{s}$ is obtained. When the vertical component of the seismic action is also considered, the differences increase to $400.8 \mathrm{KN}$ for the structure of $\mathrm{T}=0.50 \mathrm{~s}$, and $337.4 \mathrm{KN}$ for the structure of $\mathrm{T}=0.92 \mathrm{~s}$. Then, the effect of the vertical component of the acceleration on the axial forces results in average $332.7 \mathrm{KN}$ for the structure of $\mathrm{T}=0.50 \mathrm{~s}$, and $292.3 \mathrm{KN}$ for the structure of $\mathrm{T}=0.92 \mathrm{~s}$. In relation to the axial force for permanent loads $\mathrm{N}=501.5 \mathrm{KN}$, this effect means a ratio of $332.7 / 501.5=0.663$ for the first structure and $292.3 / 501.5=0.583$ for the second structure. The coefficients of variation are minimum when only the horizontal acceleration is considered and they increase to an average value of $\mathrm{COV}=0.20$ for the structure with $\mathrm{T}=0.50 \mathrm{~s}$, and $\mathrm{COV}=0.31$ for $\mathrm{T}=0.92 \mathrm{~s}$, when the vertical acceleration also acts.

The outer column, section " 3 " of Figure 1, has a significant variation in normal stress due to the effect of horizontal acceleration. For the structure of $\mathrm{T}=0.50 \mathrm{~s}$, the mean value of the maximums is $844.9 \mathrm{KN}$ in compression, compared to the 
mean value of the minimums of $-336.3 \mathrm{KN}$ in tension, with a difference of $1181.2 \mathrm{KN}$. For the structure of $\mathrm{T}=0.92 \mathrm{~s}$, the difference is $438.6 \mathrm{KN}$. The lower amplitude of axial force is due to the fact that the beams of the structure with $\mathrm{T}=0.92 \mathrm{~s}$ have lower resistance to bending that limits the shear that it transmits to the exterior columns when the energy dissipation mechanism is generated.

When the vertical component of the seismic action is also considered, the average differences increase slightly to 1235.5 $\mathrm{KN}$ for the structure of $\mathrm{T}=0.50 \mathrm{~s}$, and $461.2 \mathrm{KN}$ for the structure of $\mathrm{T}=0.92 \mathrm{~s}$. The factors with respect to the axial force due to permanent loads are reduced to $(1235.5-1181.2) / 249=0.218$, and $(461.2-438.6) / 249=0.091$, respectively. The coefficients of variation are only slightly higher than for the inner column, or the dispersion measured with the standard deviation when the mean value is very small. In summary, for the analysed structures, the influence of vertical acceleration is significant in the interior columns, while the variation of the normal stress in the exterior columns is mainly controlled by the horizontal action and the yielding of the beams that limit the shear and then they limit the axial force in the columns.

\section{Conclusions}

Two seismic resistant structures were analysed, one optimized with a fundamental period $\mathrm{T}=0.50 \mathrm{~s}$, and the other with a period $\mathrm{T}=0.92 \mathrm{~s}$ dimensioned with IC 103 , under the action of two sets of accelerograms representative of the seismicity of the site through its design spectrum. One set of accelerograms was generated numerically and the other set was selected and scaled from records of earthquakes that occurred.

The uniform scaling applied to all the components of a set of accelerograms allows considering the variability that naturally exists between one record and another, as well as the frequency content of each one. The set of accelerograms selected from the records of earthquakes that have occurred present greater variability than those generated numerically, although the mean spectra fit the design spectrum in the same way.

The results of the non-linear static analysis (push-over) show the difference in stiffness and resistance of both structures, which then allows expanding the interpretation of dynamic results due to their sensitivity to different frequencies of the accelerograms.

The structure with the highest stiffness and resistance, $\mathrm{T}=0.50 \mathrm{~s}$, presents a non-linear dynamic behaviour with the formation of the energy dissipation mechanism but with little incursion in the post-yielding behaviour. For the set of recorded accelerograms, slightly higher maximum displacements and shear base are obtained than for the set of numerically generated accelerograms, with greater dispersion quantified by the coefficients of variation for maximum displacements of 0.226 versus 0.176 .

Comparison of the maximum dynamic response in the structure with $\mathrm{T}=0.92 \mathrm{~s}$, for registered accelerograms with respect to numerically generated accelerograms, shows the same mean displacements but a maximum difference of $38 \%$ in individual results, statistically quantified by the coefficient of variation 0.434 versus 0.182 . The local moment - curvature results for beam and column sections present the same tendency as the global results of shear force - displacement, but with greater dispersions within each set of accelerograms. Average coefficients of variation of 0.754 for recorded accelerograms and 0.549 for generated accelerograms resulted for the structures analysed.

The influence of the vertical acceleration is significant in the axial force of the interior columns, with percentages with respect to the axial stress due to permanent loads of 0.663 for the structure of $\mathrm{T}=0.50 \mathrm{~s}$, and 0.583 for the structure of $\mathrm{T}=0.92$ $\mathrm{s}$. The variation of the axial force in the outer columns is controlled mainly by the horizontal action and the yielding of the beams that limit its shear and then limit the axial force in these columns.

As a final conclusion, with the results of the examples presented, and considering that seismic action is the greatest source of uncertainty in this type of analysis, it is convenient to use a set of recorded accelerograms that cause greater dispersion in the responses. The limit of the difference between the response spectrum of each individual record with respect to the mean, 
is a designer's decision based on the available seismological information. This work shows how the greater dispersion in the spectra of the accelerograms recorded has an impact on the differences in the coefficients of variation of global and local response parameters.

Author contributions: Oscar Möller conceived of the presented idea, developed the numerical models and performed the computations. Juan P. Ascheri verified the results and supervised the findings of this work. Leandro E.Nardi took the lead in writing the manuscript. All authors discussed the results and contributed to the final work.

Funding: This work was carried out with supports to the Research Project 1ING601 "Analysis and dynamic evaluation of structures considering uncertainties" granted by Secretaría de Ciencia y Tecnología from Universidad Nacional de Rosario, Argentina.

Acknowledgments: The authors express gratitude to the authorities of Instituto de Mecánica Aplicada y Estructuras (IMAE), and Consejo de Investigaciones de la Universidad Nacional de Rosario (CIUNR) for their support to develop this work within the activities of the institutions.

Conflicts of interest: The authors have no conflicts of interest to disclose.

References

ASCE 7-16. (2016). American Society of Civil Engineers.

Baker, J. W. (2011). Conditional Mean Spectrum: Tool for Ground-Motion Selection. Journal of Structural Engineering, 137(3). https://doi.org/10.1061/(asce)st.1943-541x.0000215

Bozorgnia, Y., \& Campbell, K. W. (2004). The vertical-to-horizontal response spectral ratio and tentative procedures for developing simplified V/H and vertical design spectra. Journal of Earthquake Engineering, 8(2). https://doi.org/10.1080/13632460409350486

Dehghani, M., \& Tremblay, R. (2016). Robust period-independent ground motion selection and scaling for effective seismic design and assessment. Journal of Earthquake Engineering, 20(2). https://doi.org/10.1080/13632469.2015.1051635

FEMA P-58-I. (2012). Seismic Performance Assessment of Buildings - Volume 1 - Methodology.

FEMA P-750. (2009). NEHRP recommended seismic provisions for new buildings and other structures.

Filip C. Filippou, \& Ahmad Issa. (1988). Nonlinear Analysis of Reinforced Concrete Frames Under Cyclic Load Reversals. Computers , 13(1-3).

Grant, D. N., \& Diaferia, R. (2013). Assessing adequacy of spectrum-matched ground motions for response history analysis. Earthquake Engineering and Structural Dynamics, 42(9). https://doi.org/10.1002/eqe.2270

Ha, S. J., \& Han, S. W. (2016). A Method for Selecting Ground Motions that Considers Target Response Spectrum Mean and Variance as Well as Correlation Structure. Journal of Earthquake Engineering, 20(8). https://doi.org/10.1080/13632469.2016.1138162

Hancock, J., Watson-Lamprey, J., Abrahamson, N. A., Bommer, J. J., Markatis, A., McCoy, E. M. M. A., \& Mendis, R. (2006). An improved method of matching response spectra of recorded earthquake ground motion using wavelets. Journal of Earthquake Engineering, 10. https://doi.org/10.1080/13632460609350629

INPRES - CIRSOC 103. (2018). Reglamento Argentino para Construcciones Sismorresistentes. Parte I, Construcciones en general.

Katsanos, E. I., Sextos, A. G., \& Manolis, G. D. (2010). Selection of earthquake ground motion records: A state-of-the-art review from a structural engineering perspective. In Soil Dynamics and Earthquake Engineering (Vol. 30, Issue 4). https://doi.org/10.1016/j.soildyn.2009.10.005

Möller, O., \& Foschi, R. O. (2003). Reliability Evaluation in Seismic Design: A Response Surface Methodology. Earthquake Spectra, 19(3). https://doi.org/10.1193/1.1598200

Möller, O., Foschi, R. O., Ascheri, J. P., Poliotti, M., Sierra, P. L., \& Grossman, S. (2017). Evaluación Numérica del Desempeño Sísmico Considerando Incertidumbres. Mecánica Computacional, 35, 619-635.

Möller, O., Foschi, R. O., Ascheri, J. P., Rubinstein, M., \& Grossman, S. (2015). Optimization for performance-based design under seismic demands, including social costs. Earthquake Engineering and Engineering Vibration, 14(2). https://doi.org/10.1007/s11803-015-0025-2

Pacific Earthquake Engineering Research Center. (2019). PEER Strong ground motion database. https://peer.berkeley.edu/peer-strong-ground-motion-databases 
Shinozuka, M., \& Deodatis, G. (1991). Simulation of stochastic processes by spectral representation. Applied Mechanics Reviews, 44(4). https://doi.org/10.1115/1.3119501

Taucer, F. F., Spacone, E., \& Filippou, F. C. (1991). A Fiber Beam-Column Element for Seismic Response Analysis of Reinforced Concrete Structures. In Ucb/Eerc-91/17.

Taylor, R. L., Filippou, F. C., Saritas, A., \& Auricchio, F. (2003). A mixed finite element method for beam and frame problems. Computational Mechanics, 31(1-2 SPEC.). https://doi.org/10.1007/s00466-003-0410-y



BY Ne ND Copyright (c) 2021. Möller, O., Ascheri, J. and Nardi, L. This work is licensed under a Creative Commons Attribution-Noncommercial-No Derivatives 4.0 International License. 